0

GeORgE FoX

UNIVERSITY
Digital Commons @ George Fox University

Faculty Publications - Department of Health and Human Performance

Department of Health and Human Performance

8-2019

The Influence of Change in Cardiorespiratory Fitness With Short-

Term Exercise Training on Mortality Risk From The Ball State

Adult Fitness Longitudinal Lifestyle Study

Mary T. Imboden

Matthew P. Harber

Mitchell H. Whaley

W. Holmes Finch

Derron A. Bishop

See next page for additional authors

Follow this and additional works at: https://digitalcommons.georgefox.edu/hhp_fac

Part of the Medicine and Health Sciences Commons 
Authors

Mary T. Imboden, Matthew P. Harber, Mitchell H. Whaley, W. Holmes Finch, Derron A. Bishop, Bradley S. Fleenor, and Leonard A. Kaminsky 


\title{
The Influence of Change in Cardiorespiratory Fitness With Short-Term Exercise Training on Mortality Risk From The Ball State Adult Fitness Longitudinal Lifestyle Study
}

\author{
Mary T. Imboden, PhD; Matthew P. Harber, PhD; Mitchell H. Whaley, PhD; \\ W. Holmes Finch, PhD; Derron A. Bishop, PhD; Bradley S. Fleenor, PhD; \\ and Leonard A. Kaminsky, PhD
}

\begin{abstract}
Objective: To assess the influence of changes in cardiorespiratory fitness (CRF) after exercise training on mortality risk in a cohort of self-referred, apparently healthy adults.

Patients and Methods: A total of 683 participants (404 men, 279 women; mean age: $42.7 \pm 11.0$ y) underwent two maximal cardiopulmonary exercise tests (CPX) between March 20, 1970, and December 11, 2012, to assess CRF at baseline (CPX1) and post-exercise training (CPX2). Participants were followed for an average of $29.8 \pm 10.7$ years after their CPX2. Cox proportional hazards models were performed to determine the relationship of CRF change with mortality, with change in CRF as a continuous variable, as well as a categorical variable. A Wald chi-square test was used to compare the coefficients estimating the relationship of peak oxygen consumption $\left(\mathrm{VO}_{2 \text { peak }}\right)$ at $\mathrm{CPX} 1$ with $\mathrm{VO}_{2 \text { peak }}$ measured at CPX2 with time until death for all-cause mortality.

Results: During the follow-up period there were 180 deaths. When assessed independently, there were 20\% (95\% CI, 10-49\%) and 38\% (95\% CI, 7-66\%) lower mortality risks per 1 metabolic equivalent improvement in $\mathrm{CRF}(\mathrm{P}<.01)$ in men and women, respectively, after multivariable adjustment. Those that remained unfit had $\sim 2$-fold higher risk for all-cause mortality compared with those that remained fit and CRF at CPX2 was a stronger predictor of all-cause mortality than at CPX1 $(P=.02)$.

Conclusion: Improving CRF through exercise training lowers mortality risk. Clinicians should encourage individuals to participate in exercise training to improve CRF to lower risk of mortality.
\end{abstract}

ow cardiorespiratory fitness (CRF) has been established as an important predictor of cardiovascular disease (CVD), cancer, and all-cause mortality since the late 1980s. ${ }^{1-6}$ This has been studied in various populations using a variety of methods to assess $\mathrm{CRF},{ }^{3}$ more recently including cardiopulmonary exercise testing (CPX), which is widely considered to be the gold standard method for measuring CRF. ${ }^{7,8}$

Aerobic exercise training is widely recommended, particularly in those with low CRF, to improve CRF. Exercise training programs typically result in improvements in CRF of 1 to 2 metabolic equivalents (METs) following
3 to 6 mo of moderate to vigorous exercise, which may influence mortality risk. ${ }^{9,10}$ Most investigations of the relationship between CRF and mortality have only observed the relationship from a baseline measure of CRF. ${ }^{6,11-18}$ It is presently unknown if assessing CRF after a short-term exercise training program would be more effective in determining a patient's risk, as is commonly done with other risk factors following prescribed therapies to determine effectiveness in improving patient health and reducing risk for adverse health outcomes.

The association between short-term $(<1$ year) changes in CRF post-exercise training 
and mortality risk has only been studied in patients with established CVD attending cardiac rehabilitation. Martin et $\mathrm{al}^{19}$ showed that participation in a 12-week cardiac rehabilitation program resulted in a $13 \%$ reduction in mortality with each MET increase in CRF estimated from an exercise test $\left(\mathrm{CRF}_{\mathrm{e}}\right)$ in the overall sample, and a 30\% reduction in those CVD patients categorized as low fit at baseline. However, there have been no studies that have assessed the association between change in directly measured CRF, obtained from CPX with short-term exercise training and allcause mortality in apparently healthy men and women.

Therefore, the primary aim of this study was to assess the association between changes in CPX-derived CRF following a short-term aerobic exercise training program and the risk for all-cause mortality in apparently healthy men and women. Secondly, this study aimed to compare $\mathrm{CPX}$-derived CRF measured at baseline (CPX1) to that measured after shortterm exercise training (CPX2) in predicting mortality risk.

\section{METHODS}

A sample of 683 apparently healthy participants (404 men, 279 women), ranging from 20 to 77 years of age (mean age at CPXl for total sample, $42.7 \pm 11.0 \mathrm{y}$; mean age for men, $42.2 \pm 10.6 \mathrm{y}$, mean age for women, $43.5 \pm 11.5 \mathrm{y}$ ) was obtained from the Ball State Adult Fitness Longitudinal Lifestyle Study (BALL ST) cohort between March 20, 1970, and December 11, 2012. Participants were residents of east-central Indiana who were self-referred to this university-based exercise program and were considered apparently healthy, defined as free from known CVD (history of cardiac arrest, coronary artery disease, heart failure, myocardial infarction, symptomatic valvular heart disease, peripheral artery disease, and stroke) and cancer at baseline $(n=17)$. CVD diagnosis was selfreported and verified by written physician confirmation in 24 participants; therefore, these individuals were excluded from all analyses. Participants were included if they were 18 years of age or older when they joined the program and performed two CPXs using the same mode of exercise, with CPX2 occurring after 3 to 8 months of exercise training. Participants were excluded if they did not meet the defined maximal effort criteria of a respiratory exchange ratio of $\geq 1.0$ during both exercise tests $(n=44)$, or had $<5.0$ years of mortality follow-up from the second test $(n=16)$ in an attempt to control for unknown underlying disease. This study was reviewed by the Ball State University Institutional Review Board and determined exempt as only de-identified data were used.

\section{Clinical Measurements}

A full description of the procedures involved in the resting clinical measurements performed before both CPXs has been provided previously. ${ }^{20,21}$ In summary, participants completed a health history questionnaire, providing demographic information, personal and family medical history, medication usage, and lifestyle behaviors. Information gained from the questionnaire was used to screen for medical contraindications and/or physical limitations to CPX.

Lifestyle behaviors of physical activity (PA) and smoking were self-reported. PA status was classified as inactive or active, with active being designated if participants reported engagement in regular PA, meeting the 2008 US PA recommendations for aerobic activity for adults. ${ }^{22}$ Smoking status was categorized as current smoker, including those who used cigarettes or quit within the past year, or nonsmoker at baseline.

Clinical measurements including resting heart rate, blood pressure, anthropometrics (height, weight, and waist circumference), 12-lead electrocardiogram, and blood chemistry ( $\geq 8 \mathrm{~h}$ post-prandial), were performed by trained technicians using standardized laboratory procedures. ${ }^{20,21}$ These measurements were used to determine the presence of risk factors, including obesity, hypertension, dyslipidemia, and impaired fasting glucose, defined according to current accepted atherosclerotic CVD risk factor criteria. ${ }^{23}$

\section{Assessment of CRF}

CPXs were performed using a treadmill or cycle, to determine peak oxygen consumption 
$\left(\mathrm{VO}_{2 \text { peak }}\right)$. The mode of exercise was chosen based on participant preference, comfort, and the presence of functional limitations as determined through health history questionnaire. The protocol was chosen to target achieving peak effort within 8 to 12 minutes based on the participant's self-reported PA level or $\mathrm{CRF}_{\mathrm{e}}$ obtained using a validated non-exercise prediction equation. ${ }^{21}$ Throughout the CPX, gas exchange measurements were collected using an open-circuit spirometry metabolic testing system. Standardized procedures were followed for metabolic cart calibration and all tests were supervised by trained clinical exercise physiologists, with additional medical supervision when appropriate. Participants were encouraged to exercise to volitional fatigue and a respiratory exchange ratio $\geq 1.0$ was used as an objective indicator of peak effort. $\mathrm{CRF}$ was expressed as $\mathrm{VO}_{2 \text { peak }}$ in units of $\mathrm{mL} \cdot \mathrm{kg}^{-1} \cdot \mathrm{min}^{-1}$. $\mathrm{VO}_{2 \text { peak }}$ was determined by averaging the highest two to three consecutive measured $\mathrm{VO}_{2}$ values within $2 \mathrm{~mL} \cdot \mathrm{kg}^{-1} \cdot \mathrm{min}^{-1}$, occurring in the last 2 minutes of the CPX.

\section{Exercise Training}

Following CPX1, participants were provided an individualized exercise prescription developed by clinical exercise physiologists based on their CPX results. The program consistently followed the at-the-time current recommendations first established by the American Heart Association ${ }^{24}$ and later by the American College of Sports Medicine which are updated approximately every 5 years. ${ }^{23,25}$ The exercise prescription was created with the goal of improving CRF by progressively increasing PA volume (intensity, duration, and frequency), which has previously been shown in this cohort. ${ }^{26}$ All participants who attended the program regularly, operationally defined as approximately $>75 \%$ of the sessions, were reassessed after 3 to 8 months of exercise training. CPX2 was performed using the same mode of exercise and following the same protocol as performed with CPXI.

\section{Outcomes and Follow-up}

All participants were followed from the date of CPX2 through November 2017 or until their date of death. The National Death
Index was the primary data source for obtaining vital status between 1979 and 2016. Those identified by the National Death Index as deceased due to accidental causes $(n=6)$ were excluded from analyses.

\section{Statistical Analysis}

SPSS V. 24 (SPSS, Inc., Chicago, IL), was used for all statistical analyses. Descriptive statistics were performed to summarize baseline characteristics of the participants and a univariate analysis of variance and chisquare goodness of fit test were used when appropriate to test for significant differences between sexes, CRF level (low fit [quartile I] vs fit [quartiles II, III, IV]), and vital status. A paired $t$ test was used to assess the differences between baseline CRF and CRF after exercise training, both expressed as a continuous variable $\left(\mathrm{mL} \cdot \mathrm{kg}^{-1} \cdot \mathrm{min}^{-1}\right)$. Cox proportional hazards models were used to determine hazard ratios and 95\% CIs associated with the change in CRF as related to allcause mortality for both sexes. The change in CRF was computed as the difference between baseline and post-training $\mathrm{VO}_{2 \text { peak }}$, and was used as a continuous variable in analyses. Additional models were performed with change in CRF level, as a categorical variable, as the covariate. CRF levels were initially grouped into quartiles based on the Fitness Registry and the Importance of Exercise National Database (FRIEND), ${ }^{27,28}$ which provides age- and sex-specific reference values for CPX-derived CRF for adults in the United States. Analyses were performed to determine if there were significant differences between fitness quartiles in mortality risk at baseline and post-training test. As there were no significant differences in risk between quartiles II-IV, these were grouped together and categorized as the fit group ( $\geq 26^{\text {th }}$ percentile). Quartile I was classified as the low-fit group ( $\leq 25^{\text {th }}$ percentile). The change in CRF level was then categorized into three groups, those that remained low-fit, those that remained fit, and those that improved their CRF level moving from the low-fit to fit group. The Cox proportional hazards models were fit to the data and the continuous models 
TABLE 1. Descriptive Characteristics of BALL ST Cohort at CPX1 and After CPX2

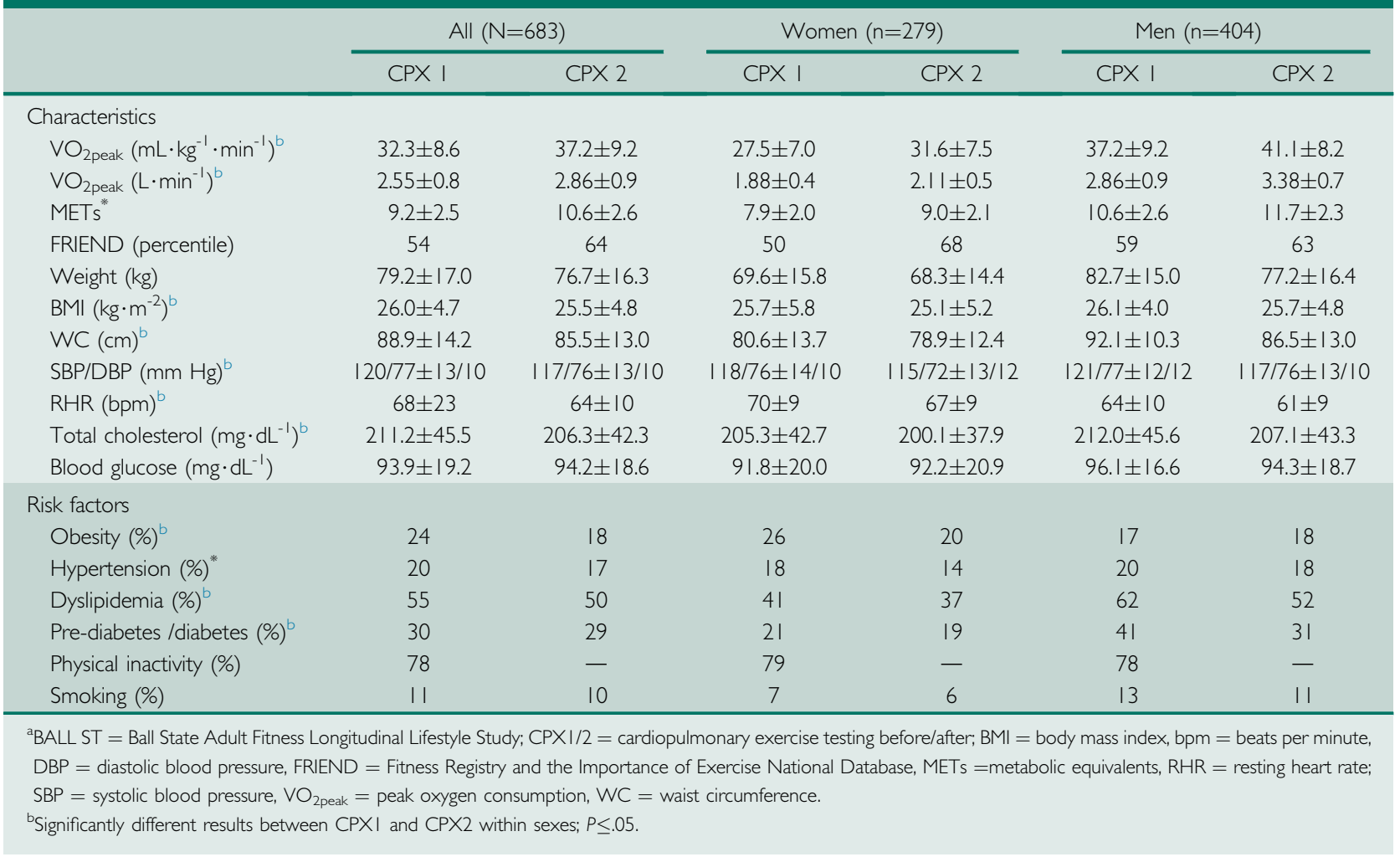

were analyzed unadjusted (model 1), adjusted for $\mathrm{VO}_{2 \text { peak }}$ at baseline (model 2), and then with further adjustment for baseline age, examination year, and the change in confounding CVD risk factors (model 3; body mass index, systolic blood pressure, fasting blood glucose, total cholesterol, expressed continuously, and smoking status), which were computed as the change in each variable between CPX1 and CPX2. The categorical models were analyzed unadjusted (model 1), adjusted for change in $\mathrm{VO}_{\text {2peak }}$ (model 2), and then with further adjustment for all variables listed in the multivariable model above (model 3). A Wald chi-square test was used to compare the coefficients estimating the relationship of $\mathrm{VO}_{2 \text { peak }}$ at $\mathrm{CPXl}$ to $\mathrm{VO}_{2 \text { peak }}$ measured at CPX2 with time until death for all-cause mortality. These models were analyzed with $\mathrm{VO}_{2 \text { peak }}$ at both tests as covariates only and then further adjusted for age and sex. To assess the assumption of proportional hazards, which underlies the Cox model, Schoenfeld residuals were examined. ${ }^{29}$ The relationships between these residuals and the model covariates were not statistically significant $(P>.05)$, indicating that the proportional hazards assumption was met.

\section{RESULTS}

$\mathrm{VO}_{2 \text { peak }}$ was $4.9 \mathrm{~mL} \cdot \mathrm{kg}^{-1} \cdot \mathrm{min}^{-1}(\sim 15 \%)$ higher $(P=.04)$ after short-term training compared with baseline for the overall sample. Further, the overall risk factor profile of subjects was improved following participation in the exercise training program (Table 1). In addition to becoming physically active, the prevalence of obesity, hypertension, and dyslipidemia were reduced $(P=.01)$.

Participants were followed for an average of $29.8 \pm 10.7 \mathrm{y}$. During this period 180 subjects died (129 men, 51 women). 
The Cox proportional hazards models showed an inverse relationship between per unit increase in $\mathrm{VO}_{\text {2peak }}\left(\mathrm{mL} \cdot \mathrm{kg}^{-1} \cdot \mathrm{min}^{-1}\right)$ and risk for all-cause mortality $(P<.05)$ (Table 2). The relationship remained significant after adjustment for baseline $\mathrm{VO}_{2 \text { peak }}$ and in the multivariable adjusted model. Specifically, a $1 \mathrm{~mL} \cdot \mathrm{kg}^{-1} \cdot \mathrm{min}^{-1}$ improvement was found to be associated with a $7 \%(95 \% \mathrm{CI}$, $2-11 \%)$ lower risk for all-cause mortality $(P=.02)$ after multivariable adjustment. This corresponded to a $25 \%$ lower risk per 1 MET improvement. The relationship between change in $\mathrm{VO}_{2 \text { peak }}$ and all-cause mortality remained significant when men and women were assessed independently (Table 2). In men, there was a $6 \%(95 \%$ CI, 3-14\%) lower risk for all-cause mortality per $1 \mathrm{~mL} \cdot \mathrm{kg}$ ${ }^{1} \cdot \mathrm{min}^{-1} \mathrm{VO}_{2 \text { peak }}(P=.01)$, after multivariable adjustment. However, the risk reduction increase was found to be greater in women, with an $11 \%$ (95\% CI, 2-19\%) lower risk per each $1 \mathrm{~mL} \cdot \mathrm{kg}^{-1} \cdot \mathrm{min}^{-1}$ increase in $\mathrm{VO}_{2 \text { peak }}$

\begin{tabular}{|c|c|}
\hline All & $\mathrm{HR}(95 \% \mathrm{Cl})$ \\
\hline Model $1^{b}$ & $0.955(0.92-0.99)$ \\
\hline Model $2^{c}$ & $0.935(0.90-0.97)$ \\
\hline Model $3^{d}$ & $0.929(0.89-0.98)$ \\
\hline $\begin{array}{l}\text { Men } \\
\text { Model I } \\
\text { Model } 2 \\
\text { Model } 3\end{array}$ & $\begin{array}{l}0.968(0.93-1.01) \\
0.937(0.90-0.98) \\
0.944(0.86-0.97)\end{array}$ \\
\hline $\begin{array}{l}\text { Women } \\
\text { Model I } \\
\text { Model } 2 \\
\text { Model } 3^{\text {e }}\end{array}$ & $\begin{array}{l}0.904(0.84-0.98) \\
0.840(0.77-0.92) \\
0.890(0.81-0.98)\end{array}$ \\
\hline $\begin{array}{l}{ }^{\mathrm{a}} \mathrm{CRF}=\text { cardi } \\
\mathrm{VO}_{2 \text { peak }}=\text { pea } \\
{ }^{\mathrm{b}} \text { Model I unadj } \\
{ }^{\mathrm{c} M o d e l} 2 \text { adjust } \\
{ }^{\mathrm{C}} \text { Model } 3 \text { adjus } \\
\mathrm{VO}_{2 \text { peak, and }} \\
\text { include body } \\
\text { blood glucose, } \\
\text { variable smokin } \\
\text { eAs there were } \\
\text { adjusted for ag } \\
\text { and change in } \\
\text { mass index, fas }\end{array}$ & $\begin{array}{l}\mathrm{HR}=\text { hazard ratio; } \\
\text { mination year, baseline } \\
\text { (continuous variables } \\
\text { blood pressure, fasting } \\
\text { is well as the categorical } \\
\text { men, the analysis was } \\
\text { year, baseline } \mathrm{VO}_{2 \text { peak, }} \\
\text { s variables include body } \\
\text { d total cholesterol). }\end{array}$ \\
\hline
\end{tabular}

(hazard ratio per $\mathrm{mL} \cdot \mathrm{kg}^{-1} \cdot \mathrm{min}^{-1}$ improvement, $0.89 ; 95 \% \mathrm{CI}, 0.81-0.98) ; P=.04$ ). The inverse relationship between per unit increase in CRF and risk for all-cause mortality was also significant with absolute $\mathrm{VO}_{\text {2peak }}$ $\left(\mathrm{L}^{\mathrm{min}}{ }^{-1}\right)(P<.05)$.

At baseline, 181 subjects (130 men, 51 women) were characterized as low-fit $\left(\leq 25^{\text {th }}\right.$ percentile). After $4.2 \pm 1.5$ months of participation in an exercise training program, 132 of these subjects (93 men, 39 women) improved their CRF to the fit category. The cumulative hazard over the follow-up period of the three CRF categories associated with the short-term training for all-cause mortality is shown in the Figure 1. Results from the Cox proportional hazards models for all-cause mortality showed those who did not improve their CRF above the low-fit threshold had an approximately 2-fold higher risk of dying from all causes compared with those who were above the low-fit threshold at both CPX1 and CPX2 $(P<.001)$. The strength of the association with mortality remained significant after further adjustment for change in $\mathrm{VO}_{2 \text { peak }}$, as well as in the multivariable adjusted model. Those who improved their CRF above the low-fit threshold had no difference in mortality rates compared with those who maintained their level in the fit classification.

Results from the Wald chi-square test of equality comparing CPX-derived CRF at baseline versus after short-term exercise training showed the value measured at CPX2 was a stronger predictor of all-cause mortality than at CPX1 $(P=.02)$ (Table 3). This relationship remained significant after further adjustment for age and sex $(P=.05)$.

\section{DISCUSSION}

This study found a strong, inverse relationship between the change in CRF after shortterm exercise training and all-cause mortality equating to a $25 \%$ ( $95 \% \mathrm{CI}, 7-38 \%$ ) lower mortality risk per MET improvement. This suggests greater improvement in CRF following short-term exercise training results in larger reductions in risk of all-cause mortality in apparently healthy adults. This 
association was independent of sex and baseline CRF and was observed over a long followup period of more than 28 years on average. This relationship remained significant when adjusted for changes in other risk factors, including body mass index, and when $\mathrm{VO}_{2 \text { peak }}$ was expressed as $\mathrm{L} / \mathrm{min}$. The exercise training resulted in a 15\% increase in CRF in our cohort, which is consistent with the expected improvement that is considered to be $5 \%$ to $30 \%{ }^{18}$ These findings further support the importance of CRF and lifestyle modifications designed to improve CRF for long-term health outcomes.

The findings from the current study also showed that CRF after short-term exercise training is a stronger predictor of mortality than a single baseline measure of CRF. This emphasizes the importance of screening for low CRF as a risk factor and subsequently prescribing an exercise training program to improve CRF. This is similar to how clinicians screen for and address other risk factors, through an initial assessment, prescription of a therapy for the risk factor, and subsequent follow-up to determine the effectiveness of the prescription in improving health outcomes.

The only other study to date that has assessed the association of changes in CRF analyzed the changes in $\mathrm{CRF}_{e}$ following a 12-week exercise training program with mortality risk was performed in cardiac patients $\left(76 \%\right.$ men; mean age, $60 \pm 10$ y). ${ }^{19}$ The patients' improvement in $\mathrm{CRF}_{\mathrm{e}}$ was ( $\sim 14 \%$ ) similar to what we observed in the BALL ST cohort. They also found an inverse relationship between $C_{R F}$ change and mortality risk; however, their observed reduction in mortality risk of $13 \%$ per MET increase was notably lower than the $25 \%$ per MET value observed in the current study. One explanation for the greater reduction in risk observed in the current study may be due to the differences in the characteristics of the cohorts (apparently healthy vs cardiac disease). However, the differences may also be due to the use of CPX to directly measure CRF in the current study versus the estimation method used in the previous study. The increased accuracy of CPX allows

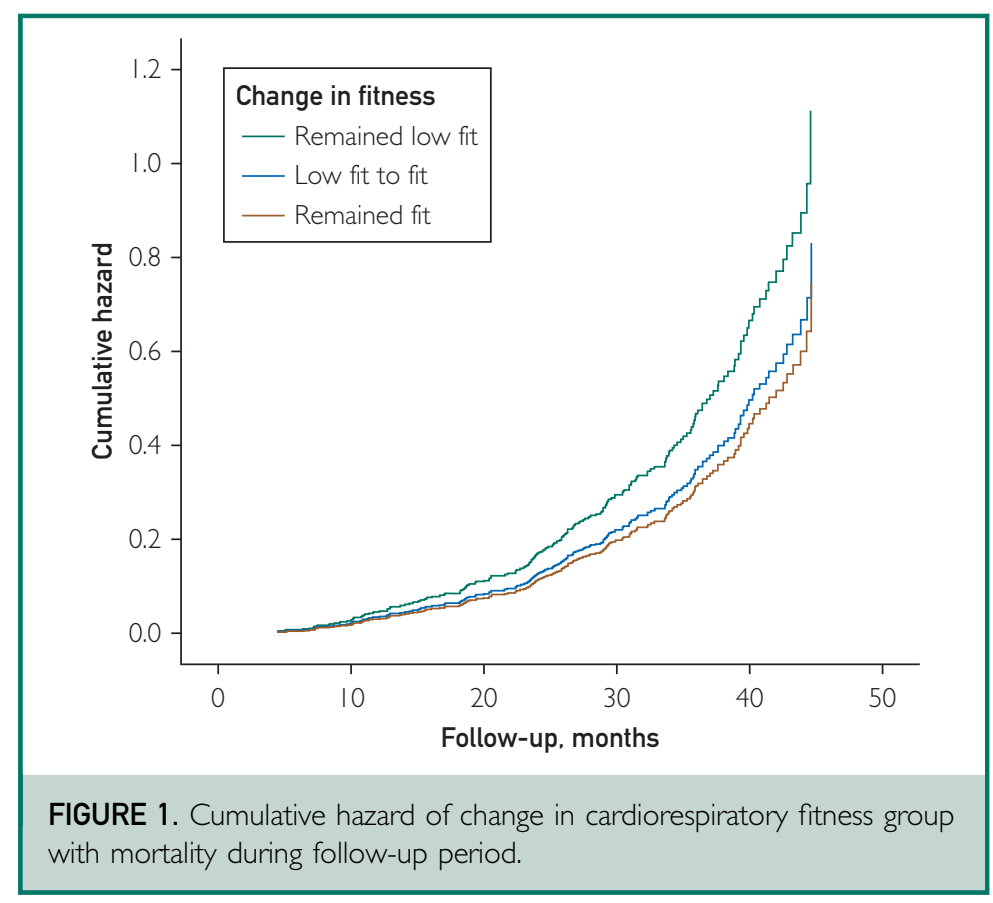

for a more precise determination of the change in CRF in response to exercise training, which may provide a more sensitive risk stratification. ${ }^{30,31}$

The current cohort was also categorized into fitness groups based on age- and sexspecific normative data from the FRIEND registry. ${ }^{27,28}$ Those who did not improve their fitness level above the $25^{\text {th }}$ percentile had an approximately 2 -fold greater risk,

TABLE 3. Comparison the Relationship Between $\mathrm{VO}_{2 \text { peak }}$ Measured at Baseline (CPX1) and After Short-Term Training (CPX2) With Mortality Outcomes $^{a}$

\begin{tabular}{|c|c|}
\hline $\begin{array}{l}\text { Wald chi-square } \\
\text { test of equality }\end{array}$ & $\begin{array}{c}\text { Absolute } \\
\text { parameter estimate }\end{array}$ \\
\hline \multicolumn{2}{|l|}{ Model $\mathrm{I}^{\mathrm{b}}$} \\
\hline $\mathrm{CPX} 2 \mathrm{VO}_{2 \text { peak }}$ & $0.047^{c}$ \\
\hline $\mathrm{CPXI} \vee \mathrm{O}_{2 \text { peak }}$ & 0.013 \\
\hline \multicolumn{2}{|l|}{ Model $2^{d}$} \\
\hline $\mathrm{CPX} 2 \mathrm{VO}_{\text {2peak }}$ & $0.035^{c}$ \\
\hline$C P X I V O_{2 p e a k}$ & 0.007 \\
\hline
\end{tabular}

${ }^{\mathrm{a}} \mathrm{CPXI} / 2=$ cardiopulmonary exercise at baseline/after, $V_{O_{2 p e a k}}=$ peak oxygen uptake.

bModel I unadjusted.

${ }^{\mathrm{c}} \mathrm{P} \leq .05$.

${ }^{\mathrm{d}}$ Model 2 adjusted for age and sex. 
compared with those who were above the $25^{\text {th }}$ percentile at both CPX1 and CPX2. The mortality risk of those who improved their fitness at CPX2 above the $25^{\text {th }}$ percentile was no different than the group who were above the $25^{\text {th }}$ percentile on both CPX. It is known that the training effect is variable for different individuals, ${ }^{32}$ and it is also understood that the rate of improvement is not uniform. ${ }^{10} \mathrm{~A}$ strength of this cohort is the wide range of demographic characteristics which likely contributed to this variation in CRF response to shortterm exercise training. These findings suggest that improvement of CRF, at least above the $25^{\text {th }}$ percentile, is important to achieve reduction in mortality risk. This shows the importance of performing periodic CRF assessments, in this case to evaluate response to short-term exercise training. Those who have not responded adequately would require modifications to their exercise prescription, as increasing exercise volume and intensity have been shown to improve CRF in individuals with a below-normal initial response. $^{32}$

Several cohorts have also assessed the association between long-term changes in CRF and mortality ( $>4$ years between assessments). ${ }^{33-38}$ All of these studies reported that maintaining or improving CRF or $\mathrm{CRF}_{\mathrm{e}}$ resulted in lower risk of mortality. However, these previous longitudinal studies did not directly assess the influence of exercise training-induced improvements in CRF on mortality risk. The current study assessed this relationship after a short-term exercise training program in apparently healthy adults and our findings support that exercise-related increase in CRF decreases mortality risk.

\section{Strengths and Limitations}

The primary strengths of this study include assessing CRF after a short-term exercise training program, examining a population of apparently healthy men and women, and directly measuring CRF with CPX. Presently there is only one other report of the CRFmortality relationship after short-term exercise training, and that was performed with cardiac patients and assessment of $\mathrm{CRF}_{\mathrm{e}}$. The BALL ST cohort also consists of men and women across a wide distribution of ages and number of risk factors and therefore may be representative of the population that many clinicians see on a regular basis. The long follow-up period is another notable strength, as it permits the understanding of how post-training improvements in CRF may alter mortality risk over time, as this study had a mean follow-up of approximately 30 years with a range of 5 to 46 years. Additionally, the use of population-specific CRF groups based on the FRIEND registry, which standardizes CRF across age- and sex-specific percentiles, ${ }^{27,28}$ increases the generalizability of our results to the US adult population, and provides clinicians with a tool to more easily interpret mortality by age and sex.

The limitations of the present study include a convenience sample of a selfreferred cohort comprised of more than $90 \%$ non-Hispanic white persons, all of whom could achieve maximal effort on an exercise test. As such, caution should be used when generalizing these results. Additionally, the low number of deaths in each CRF group, when further divided by sex, decreased statistical power for the sex-specific analyses and therefore were not performed for the categorical models. Future studies should assess the relationship between the change in directly measured CRF after short-term exercise training and all-cause mortality in men and women with a greater number of mortality outcomes, as well as in a greater distribution of racial and ethnic backgrounds. Another limitation was that lifestyle behaviors used in analyses including smoking and physical activity were self-reported. Finally, information on exercise habits and further changes in CRF following CPX2 were not available. Therefore, future studies should assess the association between changes in CRF and mortality in a large diverse cohort that has longterm exercise training adherence.

\section{CONCLUSION}

This is the first study to quantify the influence of short-term exercise training-induced changes in CRF on mortality risk in 
apparently healthy men and women. These findings show the importance of adopting exercise training as an effective method to improve CRF and decrease mortality risk. Clinicians should screen patients for low CRF, similar to their screening of other CVD risk factors and prescribe exercise training for those with low CRF and to all as a healthy lifestyle intervention. Reassessment of CRF after exercise training is important to establish if the response is adequate or if additional modifications are needed for the individual's exercise prescription.

\section{ACKNOWLEDGMENTS}

The authors thank Lynn Witty, MD, for her assistance in providing clinical feedback regarding data interpretation and for editorial feedback in the preparation of this manuscript and Leroy (Bud) Getchell, PhD, for his role is developing the Ball State University Adult Fitness Program which has led to the Ball State Adult Fitness Longitudinal Lifestyle Study.

Abbreviations and Acronyms: BALL ST $=$ Ball State Adult Fitness Longitudinal Lifestyle Study; CPX = cardiopulmonary exercise testing; $\mathbf{C R F}=$ cardiorespiratory fitness; $\mathbf{C R F}_{\mathbf{e}}=$ estimated cardiorespiratory fitness; CVD = cardiovascular disease; FRIEND = Fitness Registry and the Importance of Exercise National Database; MET = metabolic equivalent; $\mathrm{PA}=$ physical activity; $\mathrm{VO}_{2 \text { peak }}=$ peak oxygen consumption

Dr. Imboden is now with George Fox University. Newberg, OR. Support was provided, in part, from an American Heart Association Award \#I8AIREA33930023 (M.P.H.).

Potential Competing Interests: Leonard A. Kaminsky, PhD, serves as a Scientific Advisor for ENDO Medical, Inc. The remaining authors report no competing interests.

Correspondence: Address to Leonard A. Kaminsky, PhD, Ball State University, Fisher Institute of Health and WellBeing, 2000 University Ave, Muncie, IN 47306 (Kaminskyla@bsu.edu).

\section{REFERENCES}

1. Robsahm TE, Falk RS, Heir T, Sandvik L, Vos L, Erikssen J, et al. Cardiorespiratory fitness and risk of site-specific cancers: a longterm prospective cohort study. Cancer Med. 2017;6(4):865873.

2. Kodama S, Saito K, Tanaka S, et al. Cardiorespiratory fitness as a quantitative predictor of all-cause mortality and cardiovascular events in healthy men and women: a meta-analysis. JAMA. 2009;30 I (19):2024-2035.
3. Harber MP, Kaminsky LA, Arena R, et al. Impact of cardiorespiratory fitness on all-cause and disease-specific mortality: advances since 2009. Prog Cardiovasc Dis. 20 17;60(1): I I-20.

4. Lie H, Mundal R, Erikssen J. Coronary risk factors and incidence of coronary death in relation to physical fitness. Seven-year follow-up study of middle-aged and elderly men. Eur Heart J. 1985;6(2): 147- 157.

5. Slattery ML, Jacobs DR. Physical fitness and cardiovascular disease mortality: The US Railroad Study. Am J Epidemiol. 1988; 127(3):57|-580

6. Blair SN, Kohl HW, Paffenbarger RS, Clark DG, Cooper KH, Gibbons LW. Physical fitness and all-cause mortality: a prospective study of healthy men and women. JAMA. 1989;262(17):2395-2401.

7. Laukkanen JA, Lakka TA, Rauramaa R, et al. Cardiovascular fitness as a predictor of mortality in men. Arch Int Med. 200 I; |6|(6):825-83|

8. Imboden MT, Harber MP, Whaley MH, Finch WH, Bishop DL, Kaminsky LA. Cardiorespiratory fitness and mortality in healthy men and women. J Am Coll Cardiol. 2018;72(19):2283-2292.

9. Fletcher GF, Ades PA, Kligfield P, et al. Exercise standards for testing and training: a scientific statement from the American Heart Association. Circulation. 2013;128(8):873-934.

10. Garber CE, Blissmer B, Deschenes MR, et al. American College of Sports Medicine position stand. Quantity and quality of exercise for developing and maintaining cardiorespiratory, musculoskeletal, and neuromotor fitness in apparently healthy adults: guidance for prescribing exercise. Med Sci Sports Exerc. 201 I; 43(7): | 334-1359.

11. Myers J, Prakash M, Froelicher V, Do D, Partington S, Atwood JE. Exercise capacity and mortality among men referred for exercise testing. N Engl I Med. 2002;346( I I):793-80 I.

12. Sandvik L, Erikssen J, Thaulow E, Erikssen G, Mundal R, Rodahl K. Physical fitness as a predictor of mortality among healthy, middle-aged Norwegian men. N Engl J Med. 1993; 328(8):533-537.

13. Gulati M, Pandey DK, Arnsdorf MF, et al. Exercise capacity and the risk of death in women: the St James Women Take Heart Project. Circulation. 2003; I08(1 3): I 554- I559.

14. Al-Mallah $\mathrm{MH}$, Juraschek SP, Whelton $\mathrm{S}$, et al. Sex differences in cardiorespiratory fitness and all-cause mortality: the Henry Ford Exerclse Testing (FIT) project. Mayo Clin Proc. 20I 6;9I (6):755-762.

15. Faselis C, Doumas M, Pittaras A, et al. Exercise capacity and allcause mortality in male veterans with hypertension aged $>70$ years. Hypertension. 20 I 4;64(I):30-35.

16. Vanhees L, Fagard R, Thijs L, Amery A. Prognostic value of training-induced change in peak exercise capacity in patients with myocardial infarcts and patients with coronary bypass surgery. Am J Cardiol. 1995;76(14): 1014-1019.

17. Kavanagh T, Mertens DJ, Hamm LF, et al. Peak oxygen intake and cardiac mortality in women referred for cardiac rehabilitation. J Am Coll Cardioil. 2003;42(I2):2।39-2। 43.

18. Mandsager K, Harb S, Cremer P, Phelan D, Nissen SE, Jaber W. Association of cardiorespiratory fitness with long-term mortality among adults undergoing exercise treadmill testing. JAMA Netw Open. 20I8; I (6):el 83605.

19. Martin BJ, Arena R, Haykowsky M, et al. Cardiovascular fitness and mortality after contemporary cardiac rehabilitation. Mayo Clin Proc. 2013;88(5):455-463.

20. Whaley MH, Kaminsky LA, Dwyer GB, Getchell LH, Norton JA Predictors of over- and underachievement of age-predicted maximal heart rate. Med Sci Sports Exerc. 1992;24( I 0): I 173-1 179.

21. Whaley MH, Kaminsky LA, Dwyer GB, Getchell LH. Failure of predicted VO2peak to discriminate physical fitness in epidemiological studies. Med Sci Sports Exerc. 1995;27(1):85-91.

22. U.S. Department of Health and Human Services. Physical Activity Guidelines for Americans 2008

23. American College of Sports Medicine. ACSM's Guidelines for Exercise Testing and Prescription. IOth ed. Philadelphia, PA: Wolters Kluwer; 2017. 
24. American Heart Association. Exercise Testing and Training of Apparently Healthy Individuals: A Handbook for Physicians. Dallas, TX: AHA; 1972.

25. American College of Sports Medicine. Guidelines for Exercise Testing and Prescription. Ist ed. Philadelphia, PA: Lea and Febiger; 1975.

26. Getchell LH, Moore JC. Physical training: comparative responses of middle-aged adults. Arch Phys Med Rehab. 1975; 56(6):250-254.

27. Kaminsky LA, Arena R, Myers J. Reference standards for cardiorespiratory fitness measured with cardiopulmonary exercise testing: data from the Fitness Registry and the Importance of Exercise National Database. Mayo Clin Proc. 2015;90(II): 1515-1523.

28. Kaminsky LA, Imboden MT, Arena R, Myers J. Reference standards for cardiorespiratory fitness measured with cardiopulmonary exercise testing using cycle ergometry: data from the Fitness Registry and the Importance of Exercise National Database (FRIEND) Registry. Mayo Clin Proc. 2017;92(2):228-233.

29. Schoenfeld DA. Partial Residuals for the Proportional Hazards Regression Model. Biometrika. 1982;69:239-241.

30. Ross R, Blair SN, Arena R, et al. Importance of assessing cardiorespiratory fitness in clinical practice: a case for fitness as a clinical vital sign. Circulation. 2016;134(24): e653-e699.
31. Myers J. Essentials of Cardiopulmonary Exercise Testing. Champaign, IL: Human Kinetics; 1996.

32. Ross R, de Lannoy L, Stotz PJ. Separate effects of intensity and amount of exercise on interindividual cardiorespiratory fitness response. Mayo Clin Proc. 2015;90(I I):I506-I5I4.

33. Blair SN, Kohl HW, Barlow CE, Paffenbarger RS, Gibbons LW, Macera CA. Changes in physical fitness and all-cause mortality: a prospective study of healthy and unhealthy men. JAMA. 1995; 273(14): 1093-1098

34. Kokkinos P, Myers J, Faselis C, et al. Exercise capacity and mortality in older men: a 20-year follow-up study. Circulation. 20 I0; I22(8):790-797.

35. Laukkanen JA, Zaccardi F, Khan H, Kurl S, Jae SY, Rauramaa R Long-term change in cardiorespiratory fitness and all-cause mortality: a population-based follow-up study. Mayo Clin Proc. 2016;91 (9): I 183-1188.

36. Lee DC, Sui $X$, Artero EG, et al. Long-term effects of changes in cardiorespiratory fitness and body mass index on all-cause and cardiovascular disease mortality in men: the Aerobics Center Longitudinal Study. Circulation. 20 I I; 124(23):2483-2490.

37. Erikssen G, Liestol K, Bjomholt J, Thaulow E, Sandvik L, Erikssen J. Changes in physical fitness and changes in mortality. Lancet. 1998;352(9130):759-762.

38. de Lannoy L, Sui X, Lavie CJ, Blair SN, Ross R. Change in submaximal cardiorespiratory fitness and all-cause mortality. Mayo Clin Proc. 2018;93(2): 184-190. 